\title{
A conceptual framework to integrate electric vehicles charging infrastructure into the electric grid
}

\author{
Vivian Sultan, Hind Bitar, Ahmed Alzahrani, Brian Hilton* \\ Claremont Graduate University CISAT, 925 N Dartmouth Ave, Claremont 91711, United States
}

\begin{abstract}
The Electric Vehicle (EV) market is one of the most rapidly changing and fastest growing high-tech sectors in the United States. The relatively small number of large-scale public vehicle-charging stations makes recharging electric vehicles problematic, if not impossible at times. Decisions on making more charging stations are not as simple as simply opening more stations. This study aims at addressing "How to properly integrate EV charging infrastructure into the electricity system and deliver net benefits to the consumers?" To answer the research question, we have searched the background literature, conducted semi-structured interviews to develop a conceptual framework for decision-making that caters to EV owners/drivers, as well as to utilities. The utility and novelty of the solution is important to emphasize as the driving factors for this project. By developing a conceptual framework for decision making that previously didn't exist, a great amount of time is reduced for both the developers who are interested in finding the optimal locations and the utility companies who are interested in integrating the EV charging infrastructure into the electricity system in ways that deliver net benefits to utility customers, shareholders, vehicle owners, and society at large.
\end{abstract}

Keywords: Dispatchable grid resource, battery range, V2G technology

\section{Introduction}

The Electric Vehicle (EV) market is one of the most rapidly changing and fastest growing high-tech sectors in the United States. According to some recent estimates from the United States Department of Energy's Clean Cities program [1], the U.S. has approximately 482,000 EVs, 14,000 public charging stations, and 36,000 charging outlets. The U.S. market currently has over 20 electric vehicle models from 12 manufacturers. To increase the adoption and use of plug-in electric vehicles, President Obama announced the "EV Everywhere Challenge" in 2012 as a part of the Energy Department's Clean Energy Grand Challenges. It aims "to make electric vehicles more affordable and convenient to own and drive than today's gasoline-powered vehicles within the next 10 years." [2]. Similarly, a Bloomberg New Energy Finance report [3] suggests that the sale of electric vehicles will hit almost 90 times the equivalent figure for 2015 by 2040. The report also highlights that, by year 2022, electric vehicles will cost the same as their gasoline-driven equivalents, the point from where the sale of EVs will takeoff. California's target is to have 1.5 million EVs on the road by 2025, which is more than $600 \%$ increase over the roughly 200,000 EVs it has today [4]. According to Trabish [5], EV sales have already outperformed infrastructure growth, which is a problem that is expected to increase with the skyward trend of the EV sales.

The relatively small number of large-scale public vehicle-charging stations makes recharging electric vehicles problematic, if not impossible at times. Supporting California's target to have 1.5 million EVs on the road by 2025, a rapid expansion of charging infrastructure (between 150,000 and 750,000 non-home charging stations) is needed [6]. Faster adoption of EVs will require flexibility in charging. Various

\footnotetext{
*Manuscript received March 2, 2017; revised June 12, 2017.

Corresponding author. Tel.: + (818) 419-4666; E-mail address: vivian.sultan@ cgu.edu.

doi: $10.12720 /$ sgce.6.3.207-218
} 
analyses suggest that more charging stations are necessary to accommodate consumer demand for convenient electric vehicle recharging but the question is where these charging stations should be located. Decisions on making more charging stations are not as simple as simply opening more stations. The reason is that an electric charge depends on and impacts the overall electric grid in a region. Charging an electric vehicle is, in some instances, the equivalent of adding three houses to the grid and the electric grid is not ready for these stratospheric spikes in power demand [7]. Utilities need to keep a close eye on the grid constraints as they plan EV charging stations infrastructure in order to avoid grid reliability problems, power outages, and other unplanned costs that might occur due to peak demand influences and the grid overload. According to SDG\&E calculations, if California's targets by 2025 (1.5 million EVs) are all charged during peak times, it could add almost 10,000 MW of new peak load to the existing 64,000 MW load on California's grid [6].

An additional point is that deploying networks of electric vehicle (EV) charging stations can stabilize and bring benefit to the grid in locations where there is excess power. Looking at possible benefits and the new electricity grid of the future, EV charging can absorb mid-day solar over-generation and alleviate wind curtailment at night. Charging EVs when non-dispatchable assets like solar and wind generators are producing more energy can help flatten out the duck curve of demand and reduce the extent to which supply suddenly escalates. All of these characteristics reduce system costs, benefit ratepayers, and improve the profitability of generators [6].

Considering the grid capacity constraints, implications of EV charging if it is not appropriately incorporated into the electricity system, and the potential benefits of infrastructure planning, this paper addresses the research question: "How to properly integrate EV charging infrastructure into the electricity system and deliver net benefits to the consumers?" Previous literature showed insufficient attempts by researchers to provide solutions that can assist in decision-making with respect to this research question. The existing research was developed bearing in mind only the net benefits to EV owners while neglecting the electric circuit capacity constraints and the impact of the EV charging infrastructure on the electric grid. To date, there is no conceptual framework to identify the optimal locations for placing the EV charging infrastructure considering the above aspects.

This research paper is based on the process steps in Takeda, et al.'s design cycle to create the artifact/solution [8]. This cycle has five main steps, which are the awareness of the problem, suggestion, development, evaluation, and conclusion. The awareness of the problem phase has been indicated as mentioned above in the introduction and problem definition section. The suggestion phase is the decisions that have been made to develop the conceptual framework to assist in the placement of electric vehicles public charging stations. The research approach section, where the researchers indicated the steps to develop and create the framework outlines the development phase. The evaluation phase is explained in the evaluation section of the paper. The last phase is the future work and conclusion. The objective of this research is to develop a conceptual framework for decision-making that caters to both EV owners and grid operators.

This paper's authors chose Takeda et al.'s design cycle [8] because it is an early adoption of using design science research (DSR) as a research paradigm for Information Systems research projects as outlined in the MISQ 2004 paper [9]. The authors used the three design science research cycles of relevance, design, and rigor [10] to perform each of the Takeda, et al., process steps leading to the final framework in this paper after two iterations.

\section{Background Literature Review}

The demand for EVs is rapidly increasing and there are many countries that support the use of EVs, such as China and Germany [11]. In United States specifically, there is an enormous growth in using EVs [11]. From 2010 to 2015, the growth of EV sales increased by $40 \%$ in the United States, as shown in Fig. 1. 


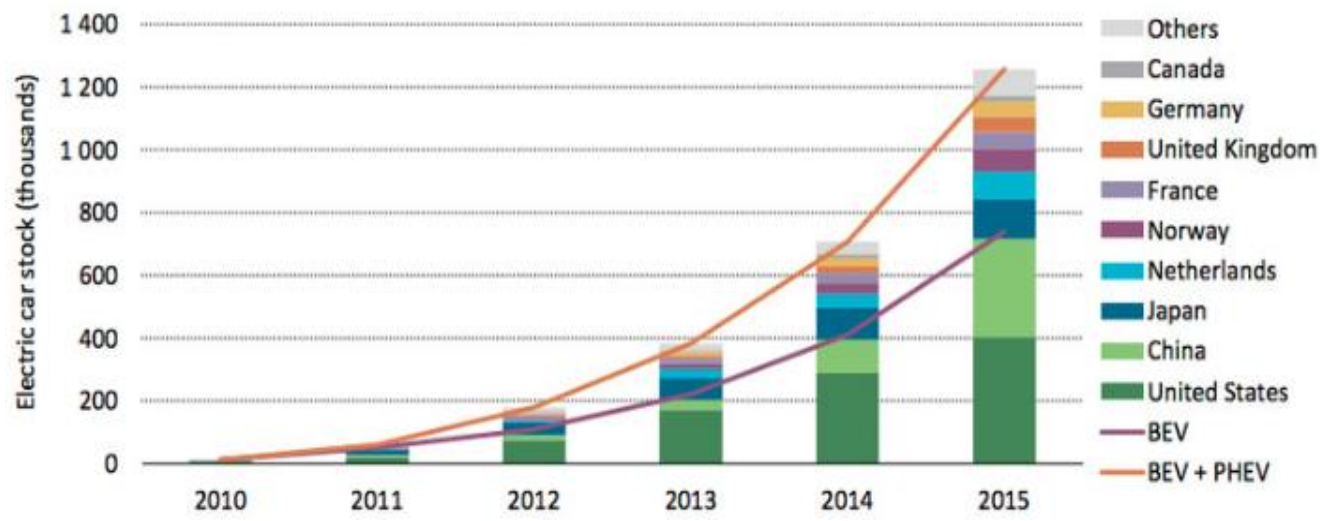

Fig. 1. The EV increased use [11].

The price of EVs is reasonable and they are considered as a second option for a personal vehicle [12]. Based on the argument of Roberts [12], EV charging stations are sufficient: "EV can already cover most trips for most people." Evidently, the current EV stations cover $87 \%$ of current trip for the 2013 Nissan Leaf [12]. With the improvement of the battery technology, the trip range will increase, the cost will go down, and the coverage will be much higher. As a result, the demand for EVs will surge.

However, as the demand for the EV rises, the supply of charging stations remains the same. Hence, there will be a shortage of EV stations where customers can recharge the car battery. The infrastructure of $\mathrm{EV}$ is currently poor and utility companies need to enhance and support this technology. Based on current data, the ratio of charging stations to EV cars is $1: 35$, which means that each station should serve $35 \mathrm{EVs}$ on average. With the rapid increase of EVs on the road, additional charging stations are needed. Moreover, Trabish [5] explained the high demand for EV public charging station adoption. The article mentioned different utility companies nationwide and their positions in adopting EV charging stations as shown in Table 1.

Table 1. Utility companies pilot programs

\begin{tabular}{|l|l|}
\hline Utilities Companies & EV Charging Stations \\
\hline Southern California Edison & Approved to build 1500 charging stations with cost around \$22 million \\
\hline San Diego Gas and Electric & $\begin{array}{l}\text { Program of Power in drive } \\
\text { In final approval phase with cost around } \$ 45 \text { million }\end{array}$ \\
\hline $\begin{array}{l}\text { Pacific Gas and Electric } \\
\text { Whe Los Angeles Department of }\end{array}$ & $\begin{array}{l}\text { Program of Charge Up LA that seeks to expand EV charging infrastructure for home } \\
\text { and workplace }\end{array}$ \\
\hline $\begin{array}{l}\text { The New England utility } \\
\text { The Hawaiian Electric Company }\end{array}$ & Appan working with the State of Connecticut on the pilot Plug My Ride rate plan \\
\hline $\begin{array}{l}\text { The State of Washington (Avista } \\
\text { Utilities) }\end{array}$ & Washington state currently has 1,544 public charging outlets. Had over 16,000 EVs \\
\hline
\end{tabular}


The US utilities have launched pilot programs recently as shown in Table 1. There are still concerns regarding whether utilities companies should implement charging stations or wait for EV adoption to spike. Trabish [5] articulates that "Providing access to charging will continue to be a challenge as EV adoption grows because rising demand has to be balanced by deliberateness in finding the right sites and in using ratepayer capital." Pilot programs are needed between state agencies, automakers, EV charging manufacturers, installers, utilities and other stakeholders. Also, there is a need for smart technologies and infrastructure planning to proactively increase utilities' grid flexibility, to reduce infrastructure costs, and to provide the charging services for EV drivers.

For example, the New England Utility began working with the State of Connecticut on a pilot program named Plug My Ride. Similarly, the Los Angeles Department of Water and Power has a program of Charge Up LA that seeks to expand EV charging infrastructure for homes and workplaces. Also, Southern California Edison was approved to build 1,500 charging stations with a cost of \$22 million. In San Diego Gas and Electric, a program named Program of Power in Drive is in its final approval phase with an estimated cost of $\$ 45$ million. As reported by Anne C. Mulkern [13], the Pacific Gas and Electric plans to install 7,600 EV Charging Stations (CSs). The proposal includes partnerships with charging companies to maintain and build the infrastructure with a total cost of $\$ 160$ million.

According to Anne C. Mulkern, the California Public Utilities Commission needed to sign the approval on the plan [13]. Although there were concerns about the size and the cost of the project, Mulkern added that the proposal had gained support from environmental organizations, automakers, and labor unions. The Pacific Gas and Electric is trying to encourage people to buy EVs through the development of charging infrastructure at workplaces, multifamily housing, including apartment buildings, and disadvantaged neighborhoods. Moreover, Mulkern explained that excess renewable energy supply from wind or solar generation is an issue that can be overcome if a utility offers incentives for drivers to charge at times when there is excess power. These pilot programs showed the serious intention of the utility companies to meet the high demand of EV charging stations in the future.

There are many studies in the literature that have tried to identify the optimal location of CSs. In 2012, Hess et al. identified mobility modeling and charging station deployment as two of the most critical tasks for the widespread adoption of electric vehicles [14]. They gave a solution for optimal placement of charging stations in a smart city where multiple information, technologies and Internet of Things solutions are integrated. Their placement approach was based on genetic programming and simulation of electric vehicles that move on a real map where streets' topologies including all the details about street type, number of lanes, speed limitations, etc. are replicated in a proportionally accurate size. The authors argued that an optimal solution for placing the charging infrastructure is based on mean trip times of electric vehicles. Additionally, Momtazpour et al. [15] proposed another approach to determine the location of EV charging stations. This approach is urban computing with clustering. Urban computing is a method that uses computational science to "foster human life in urban environments" [15]. The key elements that the researchers used in location determination of EV charging stations are places where people visit for an extended period of time. Hence, it is helpful in location identification to consider factors such as the number of times and the duration that EV owners need to charge an EV in a specific location. Furthermore, Saelee and Horanont [16] conducted an analysis study that suggests areas of CSs in Thailand. The authors selected the optimal placement of CSs based on the volume of road traffic and battery life. The authors' main assumption was that the EV owner starts to use the car fully charged. The researchers used QGIS software tools for map illustration.

Recent literature on smart grid systems is starting to pay attention to the integration of EVs into the electricity system and the impact on the grid. Kamboj et al., [17] foresaw EV owners to be consumers when they recharge their batteries through the grid. According to the authors, EVs can be used as a large distributed battery system and can provide power storage and additional services to the electric grid when they are not being driven. A 2016 study by the Electricity Innovation Lab suggests that the growing number of electric vehicle batteries offer a broad variety of valued grid services, "from demand response and voltage regulation to distribution-level services, without compromising driving experience or 
capability" [4]. The study also estimates a requirement of about 1,000-terawatt hour of additional electricity per year, or an increase of about one-quarter of our current electricity demand if all passenger cars in the U.S. were replaced with EVs. This increase in electricity demand is high enough to overload the grid and cause enormous problems.

The literature, also, confirms that EV charging can be integrated into the electricity system in ways that deliver net benefits to utility customers, shareholders, vehicle owners, and society. According to Nelder et al. [4], EV infrastructure planning can provide many benefits such as: reducing new investment in grid infrastructure, optimizing existing grid assets, prolonging their lifespans, allowing greater integration of various renewables, eliminating the need for new natural-gas generation for dispatchable capacity while reducing the curtailment of renewable production, lowering electricity and transportation costs, and increasing energy security. The authors concluded that utilities involvement in the build-out of electric vehicle charging infrastructure is in the public interest. Utilities can serve as facilitators, managers, and providers of EV charging stations.

Our review of the literature and numerous pilot projects, as well as some original modeling of state level load profiles, confirms that EV charging can be integrated into the electricity system in ways that deliver net benefits to utility customers, shareholders, vehicle owners, and society at large. A good starting point, however, is to view EV charging as a distributed energy resource that can create value for the grid. EV charging demand can be managed geographically to minimize potential increases to overall electric system costs while still meeting customers' needs.

Table 2. EVs charging levels

\begin{tabular}{|l|l|l|l|l|}
\hline Type & Voltage (V) & $\begin{array}{l}\text { Max Capacity } \\
(\mathrm{KW})\end{array}$ & $\begin{array}{l}\text { Time to charge an EV with a 60- } \\
80 \text { miles range }\end{array}$ & $\begin{array}{l}\text { Miles Range Added per } \\
\text { hour }\end{array}$ \\
\hline Level 1 & 120 & 2 & $14-22$ hours to full charge & $2-5$ \\
\hline Level 2 & 240 & 4 & $4-7$ hours to full charge & $10-20$ \\
\hline Level 3 & 480 & $20-90$ & $\begin{array}{l}30 \text { minutes to } 80 \% \text { charge at } \\
20 \mathrm{~kW}\end{array}$ & $60-80$ at $20 \mathrm{~kW}$ \\
\hline
\end{tabular}

\section{Theory and Research Approach}

According to Hevner, et al., there are three important cycles in the design science research, which are relevance, design, and rigor cycles, as it shown in Fig. 2 [10]. The authors followed and used these cycles to develop the framework by searching on the background literature and interviewing five participants who drive EVs and are employed by a major utility company in Southern California. Moreover, applying the location theory, developing and evaluating the artifact (the conceptual framework) were further steps taken by the researchers to assist developers in decision-making.

According to Durlauf \& Blume [18], location theory addresses questions of what economic activities such as EV charging stations should be located where and why. This theory is rooted in microeconomics, which studies the behavior of individual and firms in making decisions regarding the allocation of limited resources. Firms such as developers of EV charging stations/utility companies should choose locations that increase their profits and maximize the benefits to the grid. As for the EV drivers/owners, they should choose locations that maximize their utility (obtain the highest possible level of satisfaction) according to the theory. 


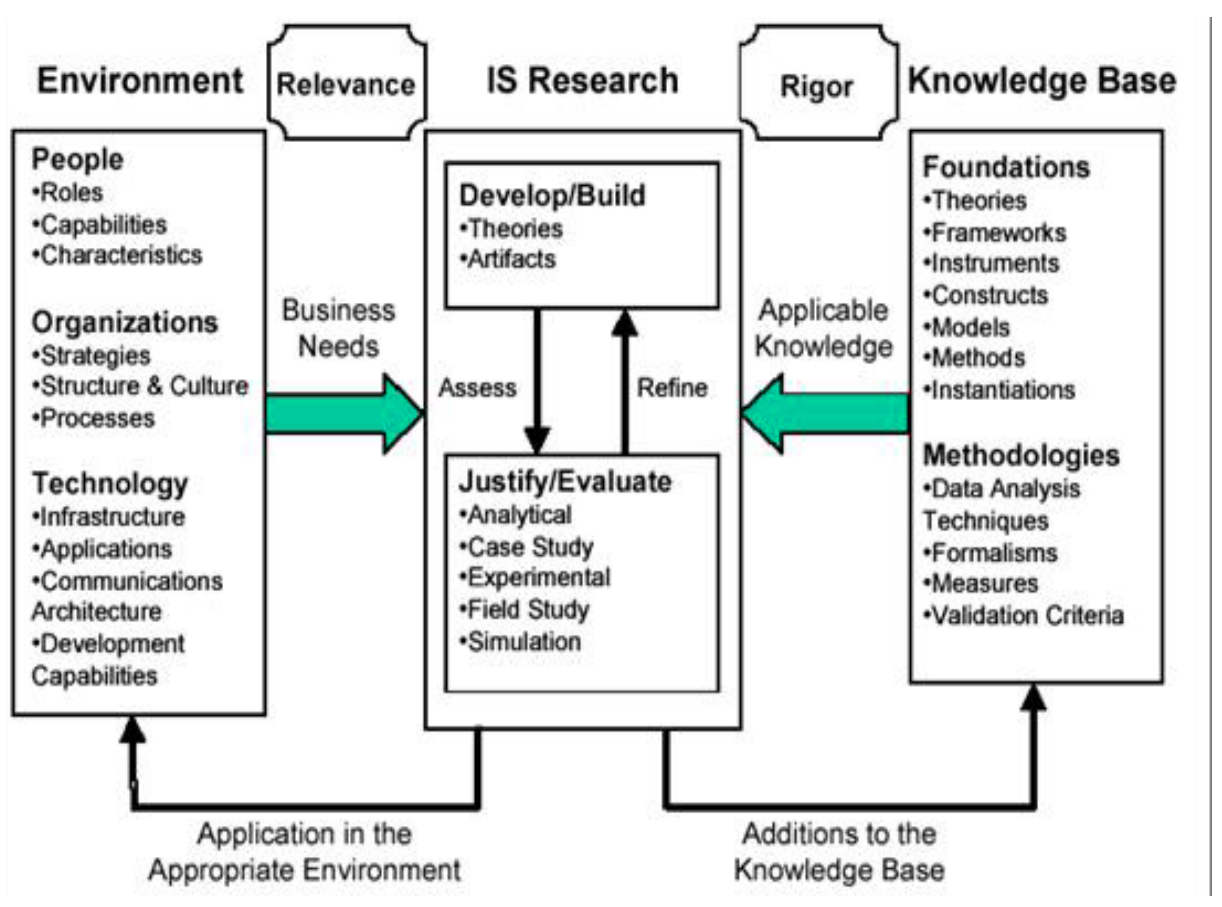

Fig. 2. Information systems research framework [10].

In this study, as it is shown in Fig. 3, we have chosen the location theory since it considers both the firms' (developers/utilities) perspective and the users' (EV owners/ drivers) perspective and this matches our research goal. Answering what and where guided mainly by the users requirements was another reason for using the location theory. We have classified the site selection factors and structured the process of the EV public charging stations site selection. Location theory's main objective is to explain why specific economic activities prefer to establish themselves in particular areas and locations by allocates with what (EVs public charging stations) and where (area, location, or regions).

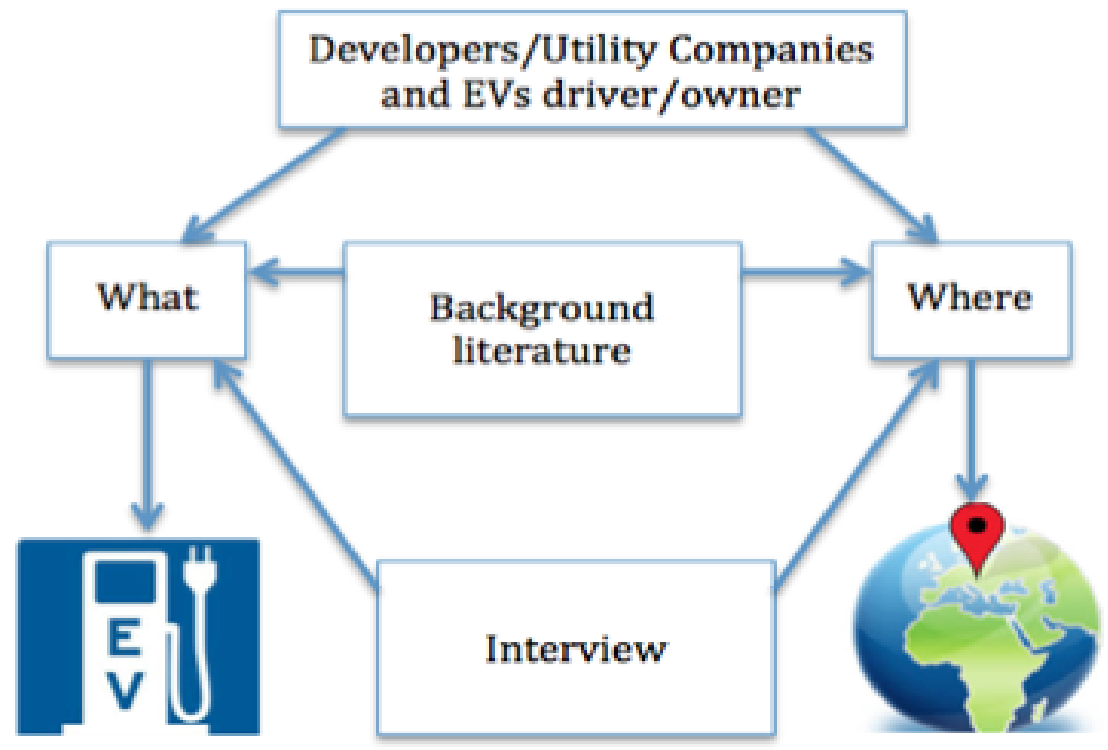

Fig. 3. EVs public charging stations location decision guided by location theory. 


\section{Artifact: Conceptual Framework}

The researchers used both the background literature and semi-structured interview as research methods to develop the conceptual framework for decision-making that caters to EV owners/drivers, as well as to utilities for it considers the impacts of the charging infrastructure placement on the grid, and the electric circuit capacity constraints as is shown in Fig. 4.

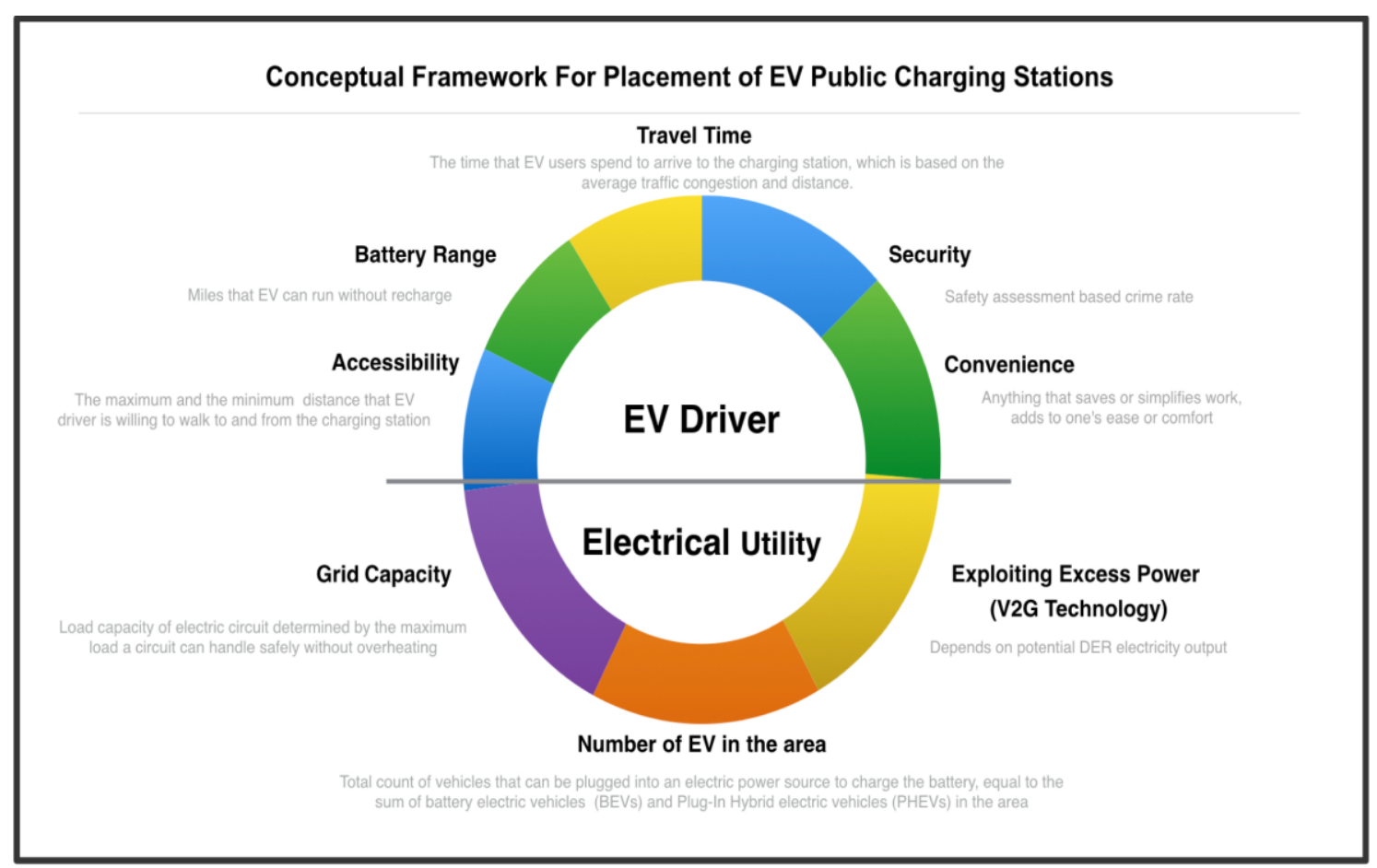

Fig. 4. Conceptual framework for placement of EV public charging stations.

Table 3. EV driver and utility's factors from literature review

\begin{tabular}{|c|c|c|c|c|c|}
\hline Factor & Definition & $\begin{array}{l}\text { Level } 2 \text { Weight } \\
\text { (Low, } \quad \text { Mid, } \\
\text { High) }\end{array}$ & $\begin{array}{l}\text { Level } 3 \\
\text { Weight (Low, } \\
\text { Mid, High) }\end{array}$ & Technical Specs. & Reference \\
\hline \multicolumn{6}{|c|}{ User Dimension - EV driver } \\
\hline Convenience & $\begin{array}{l}\text { Anything that saves or } \\
\text { simplifies work, adds to } \\
\text { one's ease or comfort, } \\
\text { which is short distance } \\
\text { and comfortable place to } \\
\text { spend time }\end{array}$ & High & High & 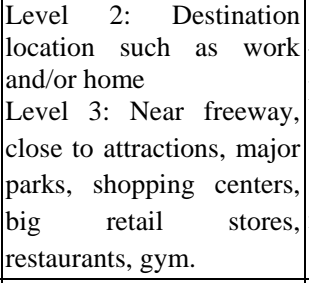 & \begin{tabular}{|l} 
Walton [12], and \\
Plumer [11]. \\
Supported \\
interviews
\end{tabular} \\
\hline Accessibility & $\begin{array}{l}\text { The maximum and the } \\
\text { minimum distance that } \\
\text { EV owners are willing to } \\
\text { walk to and from the } \\
\text { charging station }\end{array}$ & Medium & High & $\begin{array}{l}\text { Level 2: short distance } \\
(0.5 \text { mile maximum walk) } \\
\text { to destination } \\
\text { Level } 3: \text { short distance } \\
(0.25 \text { mile maximum } \\
\text { walk) to destination }\end{array}$ & Kandukuri [20] \\
\hline
\end{tabular}




\begin{tabular}{|c|c|c|c|c|c|}
\hline Travel Time & $\begin{array}{l}\text { The time that EV users } \\
\text { spend to arrive to the } \\
\text { charging station, which } \\
\text { is based on the average } \\
\text { traffic congestion (if } \\
\text { there are many ways to } \\
\text { arrive to the final } \\
\text { destination) and distance } \\
{[19] \text {. }}\end{array}$ & Medium & High & $\begin{array}{l}\text { Travel Time Index (the } \\
\text { ratio of the peak period } \\
\text { travel time as compared to } \\
\text { the free-flow travel time) }\end{array}$ & Xiong et al. [20] \\
\hline Battery Range & $\begin{array}{l}\text { Miles that EVs can run } \\
\text { without recharge }\end{array}$ & Medium & High & Maximum 50 Miles & $\begin{array}{|lr|}\text { United } & \text { States DOT } \\
\text { Federal } & \text { Highway } \\
\text { Administration [21] } \\
\text { Supported r by } \\
\text { interviews } & \\
\end{array}$ \\
\hline Security & $\begin{array}{l}\text { Safety assessment based } \\
\text { crime rate }\end{array}$ & High & Medium & Crime index & Kandukuri [20] \\
\hline \multicolumn{6}{|c|}{ User Dimension - Utility } \\
\hline $\begin{array}{l}\text { Exploiting Excess } \\
\text { Power } \\
\text { (Vehicle to Grid } \\
\text { Technology) }\end{array}$ & $\begin{array}{l}\text { A renewable energy } \\
\text { approach that aims at } \\
\text { exploiting excess power } \\
\text { by charging at locations } \\
\text { where there is potential } \\
\text { excess solar and/or wind } \\
\text { generation }\end{array}$ & Medium & High & 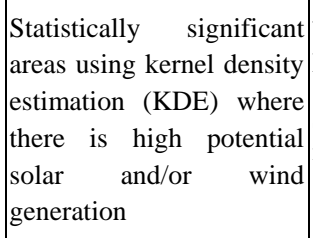 & $\mid \begin{array}{ll}\text { Woody } \quad[22] & \text { and } \\
\text { Nelder } \text { et al. }[4] . & \\
\text { Supported } & \text { by } \\
\text { interviews } & \end{array}$ \\
\hline Grid Capacity & $\begin{array}{l}\text { Load capacity of electric } \\
\text { circuits determined by } \\
\text { the maximum load a } \\
\text { circuit can handle safely } \\
\text { without overheating }\end{array}$ & Medium & High & $\begin{array}{l}\text { A minimum requirement } \\
\text { of } 12 \text { kilovolts modern } \\
\text { circuit }\end{array}$ & $\begin{array}{lrr}\text { The } & 2016 & \text { Electricity } \\
\text { Innovation } & & \text { lab } \\
\text { estimates, } & \text { Nelder } & \text { et } \\
\text { al. } \quad 4] & \text { and } & \text { Pedro } \\
\text { Pizarro, } & \text { CEO } & \text { of } \\
\text { Southern } & \text { California } \\
\text { Edison from } & \text { Julia } \\
\text { paper [23]. } & \\
\text { Supported } & & \text { by } \\
\text { interviews } & & \\
\end{array}$ \\
\hline $\begin{array}{l}\text { Number of EV in the } \\
\text { area }\end{array}$ & $\begin{array}{l}\text { Total count of vehicles } \\
\text { that can be plugged into } \\
\text { an electric power source } \\
\text { to charge the battery, } \\
\text { which is the sum of } \\
\text { battery electric vehicles } \\
\text { (BEVs) and Plug-In } \\
\text { Hybrid electric vehicles } \\
\text { (PHEVs) }\end{array}$ & High & Medium & $\begin{array}{l}\text { Statistically significant } \\
\text { areas with large number } \\
\text { of EVs (hotspot using the } \\
\text { Getis-Ord Gi* statistic) }\end{array}$ & $\left|\begin{array}{lll}\text { Momtazpour, et } & \text { al. } \\
{[15] .} & & \\
\text { Supported } & & \text { by } \\
\text { interviews } & & \end{array}\right|$ \\
\hline
\end{tabular}

Our framework has two main dimensions; the first one is the user dimension, which has two main values: (1) EVs drivers and (2) utility. The second dimension is the factors that help in decision-making for the optimal location of EVs charging stations. First, we searched in the literature and the literature evaluation produced five factors that will assist in determining the optimal location for EV drivers. Then, we considered three more factors that will aid in decision-making for utilities. All eight factors were developed from the background as is shown in Table 3.

Columns' values for Level II Weight (Low, Mid, High), Level III Weight (Low, Mid, High), and Technical Specs. were determined based on the researchers' understanding of the phenomenon, its factors, 
and the customers' requirements. Five participants, who are currently being employed by a major utility company in Southern California, were interviewed thus provided good insights from the industry perspective. The participants were selected using a purposeful sampling technique, where participants with experience driving/owing EVs were selected. The interviews ranged from 30 minutes to an hour. The profile of the sample is shown in Table 4. The data collection technique used was a semi-structured interview. More questions were developed based on the conversation between the interviewer and the interviewee ${ }^{\mathrm{a}}$.

Table 3. Sample characteristics

\begin{tabular}{|l|l|l|}
\hline Interviewee's Position & Vehicle Type, Battery Range \& Year of Make & Gender \\
\hline Participant 1 - Manager & Tesla Model S, 210 miles range, 2016 & Female \\
\hline Participant 2 - Director & Tesla Model S, 265 miles range, 2014 & Male \\
\hline Participant 3- Vice President & Chevy Volt, 40 miles range, 2012 & Male \\
\hline Participant 4 - Project Manager & Tesla Model S, 265 miles range, 2014 & Male \\
\hline Participant 5 - Project Manager & Hyundai Sonata, 27 miles range, 2016 & Female \\
\hline
\end{tabular}

According to participant 1 who is a manager currently involved in a project for EV charging, "There is no collective strategy for placement of EV charging stations. Whichever corporation decides to invest in building public charging stations can do that in non-coordinated ways. Public charging stations are currently being built on an ad hoc base; there are no holistic strategies or coordinated efforts to build the public charging infrastructure." The researchers analyzed the interviewees' answers and generated five factors that were also supported by the literature review to influence the decision-making with respect to the placement of electric vehicles charging stations as shown in Table $5^{1}$.

Table 4. Factors supported by interviews

\begin{tabular}{|c|c|}
\hline Factor & Quote Example \\
\hline Convenience & $\begin{array}{c}\text { Dimension of EV driver } \\
\text { "It is important to have more visibility of EV charging stations to overcome the perception of } \\
\text { shortage.... " } \\
\text { "I can charge it at a hotel overnight if I am spending the night at a hotel" } \\
\text { "Variety of locations: at home, workplaces, malls, and next to freeway..." } \\
\text { "...such as shopping malls, Costco, and the gym" }\end{array}$ \\
\hline
\end{tabular}

${ }^{a 1}$ To get the tabular summary of the interviews, contact the first author at vivian.sultan@cgu.edu 


\begin{tabular}{|c|c|}
\hline Battery Range & $\begin{array}{l}\text { "I have a range greater than } 100 \text { miles, my daily use doesn't exceed } 100 \text { miles" } \\
\text { "My daily commute is about } 60 \text { miles per day" }\end{array}$ \\
\hline & Dimension of Utility \\
\hline $\begin{array}{l}\text { Vehicle-to-grid } \\
\text { (V2G) } \\
\text { technology/ } \\
\text { Exploiting Excess } \\
\text { Power }\end{array}$ & $\begin{array}{l}\text { ".. so more public charging stations will be needed during the day to take advantage of the excess solar } \\
\text { power and the cheaper price of electricity..." } \\
\text { "Now the cheapest time to charge your vehicle is in the middle of the night but with the additional } \\
\text { solar power, things might change..." } \\
\text { "... Utility companies need sales growth from electrification of vehicles to offset the reduction of } \\
\text { electricity consumption that will result from potential solar generation. In other words, electrification } \\
\text { of vehicles will help in keeping electricity rate from increasing so that customers are happy. Another } \\
\text { point is that the electrification of vehicles can help the state in meeting its aggressive Greenhouse Gas } \\
\text { (GHG) goals..." } \\
\text { "...I will not want to risk the degradation of my car battery by using it as a vehicle to grid (V2G) to } \\
\text { provide demand response services to the grid..." } \\
\text { "... using the EV battery as a dispatchable distributed energy resource (DER) could be interesting and } \\
\text { beneficial but my decision will depend on how much I will get paid." }\end{array}$ \\
\hline Grid Capacity & $\begin{array}{l}\text { "From a utility perspective, our role is to prepare the infrastructure and to create value from building } \\
\text { charging stations..." } \\
\text { "...There will be a time when workplace charging might be cheaper than charging at home..." }\end{array}$ \\
\hline $\begin{array}{c}\text { Number of EVs in } \\
\text { the area }\end{array}$ & $\begin{array}{l}\text { “...You definitely need to prioritize (based on number of EVs in the area). However, in order for EV } \\
\text { to go mainstream, you need to have public charging stations in disadvantaged neighbourhoods as well. } \\
\text { You won't have product mainstream unless all people can afford it. So if you compare an EV with a } \\
\text { product that went mainstream such as the cell phone, all people (rich as well as those who live in } \\
\text { disadvantaged neighbourhoods) have it." }\end{array}$ \\
\hline
\end{tabular}

\section{Evaluation}

The project team applied a qualitative interview method to evaluate the prototype using socio-technical technique to assess the following metrics: propriety and utility. The researchers evaluated the different values held by the different stakeholders by sending the following five interview questions via email: (1) how useful is the conceptual framework (Fig. 4.) in your view? (2) Is the framework complete from your perspective? (3) Do you agree with the factors' definitions in table 3? (4) Do you agree with the factors' technical specifications in table 3? (5) What changes would you recommend for improvement? In this case, both EV drivers' and utility executives' perspectives were part of the evaluation process to ensure that their unique stances were understood.

Feedback was solicited from participants who were previously involved in the awareness of the problem phase and gathering the requirements. Two participants responded with positive feedback and they highlighted the potential offered by the proposed artifact. According to Jim Horstman, a utility industry consultant, the conceptual framework is useful and he agreed with the factors' definitions. However, Horstman pointed out that there is an overlap of some factors such as the Accessibility, Convenience and Travel Time. Horstman suggested that all three factors could be considered under Convenience.

As for the feedback from the second participant, who is a director with a utility company, he advised to have charging time as a separate characteristic in the conceptual framework. He noted that not all vehicles can accept charging from Level 2 and Level 3 chargers and this characteristic might be linked to the number of vehicles in the area. He generally agreed with the factors' definitions, with the exception of convenience. According to the utility director, "there is great potential in the research direction because it will help solve a pressing problem facing electric utilities, particularly electric utilities that will have substantial distributed energy resources (DERs) on their systems." 


\section{Limitations and Future Work}

The artifacts proposed in this paper used literature review and interviewees' feedback to develop a solution that caters to both EV owners and grid operators. The suggested framework aimed at providing a solution for decision-making to place the EV charging stations in locations that consider net benefits to EV drivers/owners and the potential benefits to the grid. This could potentially save time and resources for developers and utility companies who are interested in the identification of optimal locations for the placement of EV public charging stations.

Another limitation is in the evaluation phase. It is important to recognize that the time constraint imposed limitations on the evaluation and what these limitations are. The researchers don't have an opportunity to perform further iterations to improve the framework. The project team was able to interview two participants since the beginning (problem identification). However, they need to get and address the interviewees' suggestions to complete the research.

The utility and novelty of the solution is important to emphasize as the driving factors for this project. By developing a conceptual framework for decision making that previously didn't exist, a great amount of time is reduced for both the developers who are interested in finding the optimal locations and the utility companies who are interested in integrating the EV charging infrastructure into the electricity system in ways that deliver net benefits to utility customers, shareholders, vehicle owners, and society at large.

In future DSR cycles, the project team will address all of the suggestions from interviewees. The project team will develop a Geographic Decision Support Systems (GDSS) prototype to provide an instance of or concrete evidence in support of the conceptual framework. A GDSS prototype is a good starting point to illustrate how EV charging demand can be managed geographically to minimize potential increases to overall electric system costs while still meeting customers' needs. The prototype will run on a public server to give the research participants access to the application.

According to participant 4, "Something to look at is how Tesla put chargers as they put them in the right place, near freeways, exactly where I would stop. The non-Tesla charging stations are kind of hard to find." As part of future work, the project team will further research the location characteristics of Tesla super chargers and ensure that these characteristics are incorporated into the conceptual framework. Also, multiple tools can be developed for the purpose of building an interactive, computer-based system where developers/utilities are allowed to configure their own criteria for decision-making.

\section{Conclusion}

This study aimed at addressing "How to properly integrate EV charging infrastructure into the electricity system and deliver net benefits to the consumers?" To answer the research question, we have searched the background literature, conducted semi-structured interviews to develop a conceptual framework for decision-making that caters to EV owners/drivers, as well as to utilities. The framework we offer in this paper is the first, to date, to address the research question. Our proposal was developed bearing in mind not only the net benefits to EV owners but also the electric circuit capacity constraints and the impact of the EV charging infrastructure on the electric grid.

From this research, we conclude that EV charging demand can be managed geographically to minimize potential increases to overall electric system costs while still meeting customers' needs. If additional funds and data are made available, a custom GDSS solution can be developed to allow EV charging developers to configure their own criteria for decision-making.

\section{References}

[1] United States Department of Energy's Clean Cities program. (2015). Alternative Fuels Data Center: electric vehicle charging station locations. [Online]. Available: http://www.afdc.energy.gov/fuels/electricity_locations.html

[2] United States Department of Energy. (2012). President Obama launches EV-everywhere challenge as part of energy 
department's clean energy grand challenges. [Online]. Available: http://energy.gov/articles/president-obama-launches-eveverywhere-challenge-part-energy- department-s-clean-energy

[3] California Public Utility Commission. (2015). Electric vehicles to be $35 \%$ of global new car sales by 2040. [Online]. Available: https://about.bnef.com/press-releases/electric-vehicles-to-be-35- of-global-new-car-sales-by-2040/

[4] Nelder C, Newcomb J, Fitzgerald G. (2016). Electric vehicles as distributed energy resources. [Online]. Available: http://www.rmi.org/pdf_evs_as_DERs

[5] Trabish HK. (2016). If you build it, will they charge? Utilities cautious in plans to spur electric vehicle adoption. [Online]. Available: http://www.utilitydive.com/news/if-you- build-it-will-they-charge-utilities-cautious-in-plans-to-spur-elec/423982/

[6] SDG\&E. (2015). Electric vehicle grid integration. [Online]. Available: http://www.westernlampac.org/2015 Spring Conference/Laura McDonald EVGI LAMPAC Presentation 042715.pdf

[7] Bullis K. (2013). Could electric cars threaten the grid? [Online]. Available: https://www.technologyreview.com/s/518066/could-electric-cars-threaten-the-grid/

[8] Takeda H, Veerkamp P, Yoshikawa H. Modeling design process. AI magazine, 1990; 11(4):37.

[9] Hevner A, March S, Park J, Ram S. Design science in information systems research. MIS Quarterly, 2004; 28(1):75-105.

[10] Hevner A. A three-cycle view of design science research. Scandinavian Journal of Information Systems, 2007; 19(2):87-92.

[11] Plumer B. (2016). The rapid growth of electric cars worldwide, in 4 charts. [Online]. Available: http://www.vox.com/2016/6/6/11867894/electric-cars-global-sales

[12] Walton R. (2016). California: location matters: utilities focus on charger placement to drive electric vehicle adoption: two EV pilot programs demonstrate that just building charging stations isn't enough. [Online]. Available: http://www.utilitydive.com/news/location-matters-utilities-focus-on-charger-placement-to-drive- electric-ve/425276/

[13] Mulkern AC. (2016). California: PG\&E may build nation's largest deployment of EV charging spots. [Online]. Available: http://www.eenews.net/stories/1060042082?utm_source=Sailthru\&utm_medium=email\&utm_c ampaign=Issue: 2016-08-30 Utility Dive Storage \%5Bissue:7084\%5D\&utm_term=Utility Dive: Storage

[14] Hess A, Malandrino F, Reinhardt M, Casetti C, Hummel K, Barcelo-Ordinas J. (2012). Optimal deployment of charging stations for electric vehicular networks, proceedings of the first workshop on urban networking. [Online]. Available: http://conferences.sigcomm.org/co-next/2012/eproceedings/urbane/p1.pdf

[15] Momtazpour M, Butler P, Hossain MS, Bozchalui MC, Ramakrishnan N, Sharma R. Coordinated clustering algorithms to support charging infrastructure design for electric vehicles. In: Proc. of the ACM SIGKDD International Workshop on Urban Computing, 2012:126-133.

[16] Saelee S, Horanont T. Optimal placement of EV charging station considering the road traffic volume and EV running distance. Journal of Traffic and Logistics Engineering, 2016; 4(1).

[17] Kamboj S, Kempton W, Decker KS. Deploying power grid-integrated electric vehicles as a multi-agent system. Presented at: 2011 the International Conference on Autonomous Agents and Multi-agent Systems (AAMAS).

[18] Durlauf SN, Blume LE. The New Palgrave Dictionary of Economics. Basingstoke: Palgrave Macmillan; 2008.

[19] Kandukuri Y. (December 2013). A dynamic GIS model for optimum location identification of plug-in-electric vehicle charging stations. [Online]. Available: https://etd.ohiolink.edu/rws_etd/document/get/akron1384806074/inline

[20] Xiong Y, Gan J, An B, Miao C, Bazzan AL. Optimal electric vehicle charging station placement. In: Proc. of the 24th International Joint Conference on Artificial Intelligence. 2015:2662-2668.

[21] United States Department of Transportation Federal Highway Administration. (2014). Office of highway policy information national household travel survey. [Online]. Available: http://www.fhwa.dot.gov/policyinformation/pubs/pl08021/fig4_5.cfm

[22] Woody $T$ (June 2007). PG\&E's battery power plans could jump start electric car market. [Online]. Available: http://thegreenwombat.com/2007/06/12/pges-battery-power-plans-could-jump-start-electric-car-market/

[23] Pyper J. (October 2016). New Edison international CEO Pizarro calls for greater grid investment to enable change. [Online]. Available: https://www.greentechmedia.com/articles/read/New-Edison-CEO-Pizarro-Calls-for-Greater-Grid-Investment-toEnable-Change 